引用格式: 赵否, 唐承财. 产业结构变迁、旅游业与经济增长一一来自中国的经验证据[J]. 资源科学, 2017,39(10): 1918-1929. [Zhao L, Tang C C. China's tourism industry, industrial structure and economic growth[J]. Resources Science, 2017, 39 (10) : 19181929.] DOI: $10.18402 /$ resci.2017.10.11

\title{
产业结构变迁、旅游业与经济增长 来自中国的经验证据
}

\author{
赵 磊 ${ }^{1}$, 唐承财 ${ }^{2}$
}

(1. 浙江工业大学经贸管理学院,杭州 310023 ; 2. 北京第二外国语学院旅游管理学院, 北京 100024)

摘 要: 既有关于旅游业导向型经济增长假说的经验研究, 由于忽视了产业结构变迁的动态性, 从而会导致对 旅游业影响经济增长效应的估计偏误。因此, 本文在定量测度中国各省产业结构变迁基础上,将旅游业、产业结构 变迁与经济增长纳入到统一分析框架进行实证考察, 以拓展旅游业导向型经济增长假说的研究体系。研究结果表 明: (1) 以泰尔指数反向度量的产业结构合理化对经济增长具有抑制作用, 而产业结构高级化则对经济增长具有积 极作用, 并且产业结构高级化对经济增长的“结构效应”要大于产业结构合理化对经济增长的“失衡效应”; (2)中国 旅游业对经济增长具有显著的正向影响, 与此同时, 产业结构欠缺合理化抑制了旅游业对经济增长的影响效应, 而 产业结构高级化可正向调节旅游业对经济增长的影响效应。本文认为, 政府在进行产业结构调整时, 除应着重强 调产业结构高级化的同时, 还需高度关注产业结构合理化, 从而为发挥产业结构变迁对旅游业影响经济增长的正 向调节作用创造条件。

关键词: 旅游业; 产业结构合理化; 产业结构高级化; 经济增长; 中国

DOI: $10.18402 /$ resci.2017.10.11

\section{1 引言}

进人 21 世纪,无论是全球范围,还是中国现实, 旅游业已冊容置疑地成为国家和地区经济增长的 重要动力。根据世界旅游组织 (http://www2.unwto. org / ) 最新统计数据, 2015 年, 全球游客数量达 11.84 亿人次, 旅游收人总计 1.4 万亿美元, 比上年分别上 升了 $4.4 \%$ 和 $3.6 \%$, 旅游业对全球国内生产总值的 综合贡献达 7.8 万亿美元, 占全球国内生产总值总 量的 $10 \%$, 旅游业收人占世界出口额为 $7 \%$, 其增速 也超过了世界商品贸易 $2.8 \%$ 的增速。与此同时, 中 国旅游业总收人达 4.13 万亿人民币，同比增长 $11 \%$, 旅游业对国内生产总值直接贡献为 3.32 万亿 元, 综合贡献为 7.34 万亿元, 分别占国内生产总值 的 $4.9 \%$ 和 $10.8 \%$ 。对比来看, 中国旅游业对经济增
长的综合贡献率略高于世界水平。因此, 聚焦中国 情境下旅游业对经济增长的影响研究成为旅游经 济学领域的学术关切。尤其是, 深人揭示由旅游业 促进经济增长而形成的旅游导向型经济增长 (Tourism-Led Growth, TLG) 假说在中国案例的生 成机制, 更加需要学者们应从多维视角对该理论命 题进行实证探析。

中国经济在经历高速增长之后, 伴随着的核心 学术思考是关于经济增长源泉的广泛讨论。基于 新古典增长理论和新增长理论的研究主要是从资 本投资、生产效率、人力资本和市场改革等视角来 解释中国经济的增长 ${ }^{[1-4]}$ 。然而, 这些研究遗漏了结 构主义学派所推崇的产业结构变迁因素, 而其基本 立论在于,生产要素从低效率部门向高效率部门转

收稿日期: 2017-06-12; 修订日期: 2017-08-08

基金项目: 国家社会科学基金项目(14CGL023); 国家自然科学基金项目(41301161); 北京市属高校高水平教师队伍建设支持计划青年 拔尖人才培育计划项目(CIT\&TCD201704067)。

作者简介: 赵否, 男,山东新泰人,博士,副教授,硕士生导师,研究方向为旅游经济学。E-mail: leizhde1984@126.com 通讯作者: 唐承财,E-mail : tcc5808@163.com 
移, 以获得资源配置的“结构红利”, 是保证经济可 持续增长的重要源泉 ${ }^{[5]}$ 。需要注意的是,产业结构 因素在国内外TLG假说实证框架中均已有所体现 ${ }^{[6-10]}$, 但仍存在两点弊端: (1)忽视了产业结构的动态变迁 过程。经典的产业结构三大理论,配第一克拉克定 理、霍夫曼定理和库兹涅茨法则均指出产业结构变 迁与经济增长存在密切关系, 但既有 TLG 计量方程 设定中, 对产业结构变量的构造仅是停留在静态层 面的比例配置,忽视了产业间的动态调整。(2)忽视 了产业结构变迁的调节作用。从供给侧考虑, 旅游 业对经济结构调整具有敏感性,甚至存在一定程度 的依赖性 ${ }^{[11]}$, 这是由旅游业生产要素的综合性所决 定,所以产业结构在不同变迁阶段,为了实现新的 旅游业供求均衡, 旅游业对经济增长的影响效应和 机制也必然会存在差异性,并且由于产业结构变迁 因素并未被纳人到旅游业影响经济增长的实证研 究框架, 从而导致对 TLG 假说的实证检验会出现扭 曲偏误。

随着当前中国经济由快速增长渐次进人新常 态, 产业结构变迁因素仍是推动中国经济增长的直 接动因。与此同时,旅游业作为重要的现代服务业 部门,产业结构在调整过程中为旅游业发展创造并 提供所需的要素条件,不仅是支撑旅游业规模发 展,更是提升旅游业经济贡献率的重要保障。鉴于 此, 为了拓展中国 TLG 假说研究框架, 丰富国内旅 游经济学研究体系, 本文将旅游业、产业结构变迁 与经济增长纳人到统一分析框架进行理论阐释与 实证检验。与既有研究相比,本文研究创新体现在 以下方面：

(1) 在研究视角上,本文对中国 TLG 假说的实 证研究进行了大胆推进和突破,即首次将产业结构 变迁因素纳人到 TLG 假说的实证研究框架, 而摒弃 将产业结构仅是作为静态控制变量的传统方式,同 时在更加契合现代经济发展规律的基础上赋予产 业结构以“动态”涵义, 其研究目的在于,一方面实 证检验产业结构变迁因素在中国情境中 TLG 假说 检验中是否存在影响作用; 另一方面若存在影响, 则对中国旅游业和经济增长之间的关系进行重新 检验与评估。

(2)在研究内容上,产业结构变迁不仅是经济
增长的重要引擎, 也是促进旅游业发展的供给动 力, 在中国特殊经济背景下, 探索 TLG 假说的内在 机制, 显然不应忽视并割裂旅游业与产业结构变迁 之间的相互作用关系，而本文对含有产业结构变迁 因素的 TLG 假说进行实证检验,这在国内旅游经济 学领域尚属首次,更是对中国 TLG 假说研究框架的 切实推进与创新。

\section{2 事实判断与理论分析}

\section{1 产业机构变迁与旅游业的事实判断}

\subsection{1 产业结构变迁分析}

产业结构的动态变迁是经济增长的内在需求 和主要推力。无论是前期工业化阶段,为中国快速 经济增长所驱动的 “结构性增速” ${ }^{[12]}$, 抑或当前工业 化向城镇化跃迁时,由于产业结构的调整而诱发的 经济增长的“结构性减速” ${ }^{[13]}$, 产业结构变迁对整个 宏观经济的增长与波动均带来了深刻变革。同时, 旅游业作为地区经济增长的新生力量, 甚至是一些 地区的主导产业,因其内在属性所具有的行业敏感 性特征,也不可避免地受到产业结构变迁的影响。

本文首先对产业结构变迁进行测度, 以揭示并 提供中国产业结构变迁的基本特征和客观证据。 基于海明距离的传统 Moore 指数算法尽管可以表 征产业结构的动态变迁,但其弱点在于无法有效刻 画产业结构变迁的升级趋势。因此,为了兼顾产业 结构变迁的动态性和方向性,本文借鉴张勇等与孙 叶飞等对传统 Moore 指数的拓展思路 ${ }^{[14,15]}$, 对 Moore 指数改进后的测度公式为:

$$
\begin{aligned}
\text { Moore }_{i, t+1}^{i, j}= & \frac{\sum_{k \neq j}\left(p_{i, t}^{k}\right)^{2}+p_{i, t}^{k} \times p_{i, t+1}^{k}}{\sqrt{\sum_{k=1}^{m}\left(p_{i, t}^{k}\right)^{2} \times\left[\sum_{k \neq j}\left(p_{i, t}^{k}\right)^{2}+\left(p_{i, t+1}^{j}\right)^{2}\right]}} \times \\
& \frac{\sum_{k \neq j}\left(p_{i, t+1}^{k}\right)^{2}+p_{i, t}^{k} \times p_{i, t+1}^{k}}{\sqrt{\sum_{k=1}^{m}\left(p_{i, t+1}^{k}\right)^{2} \times\left[\sum_{k \neq j}\left(p_{i, t+1}^{k}\right)^{2}+\left(p_{i, t}^{j}\right)^{2}\right]}} \\
\text { Moore }_{i, t+1}^{i}= & \sum_{j=1}^{m} j \times p_{i, t}^{j} \times \text { Moore }_{i, t+1}^{i, t}
\end{aligned}
$$

式中 $i$ 为地区; $t$ 为时期 $; j$ 为产业; $m$ 为产业部门; $p_{i, t}^{j}$ 为 $i$ 地区 $t$ 时期该产业的级别 $j$ 占国内生产总值比; $p_{i, t}^{k}$ 为 $i$ 地区 $t$ 时期 $k$ 个产业部门占国内生产总值比 值; Moor $_{i, t+1}^{i, j}$ 为 $i$ 地区的 $j$ 产业从 $t$ 期到 $t+1$ 期的产业 结变迁指数; Moor $e_{i, t+1}^{i}$ 为 $i$ 地区产业从 $t$ 期到 $t+1$ 期 
的产业结变迁指数。以上产值数据来源于《中国统 计年鉴 $\rangle^{[16]}$ 。

基于公式(1)和公式(2),利用1999-2013 年省 际三次产业产值数据, 可计算得到省际和全国历年 产业结构相对上一期产业结构的高级化变迁程度 的测度数值。如图 1 所示, 2000-2013 年期间中国省 际三次产业结构变迁分别呈现出三个方面的特征, 即整体平稳、阶段波动和地区差异。在样本期内, 如表 1 所示, 中国省际产业结构在阶段波动中以相 对稳定的速度逐渐升级变迁, 同时表现出一定的地 区差异, 例如, 北京产业结构跨期变迁 Moore 值最 高(平均 2.685 ), 河南则最低 (平均 2.137), 说明北京 产业结构变迁速度最快, 河南则最慢。从全国来

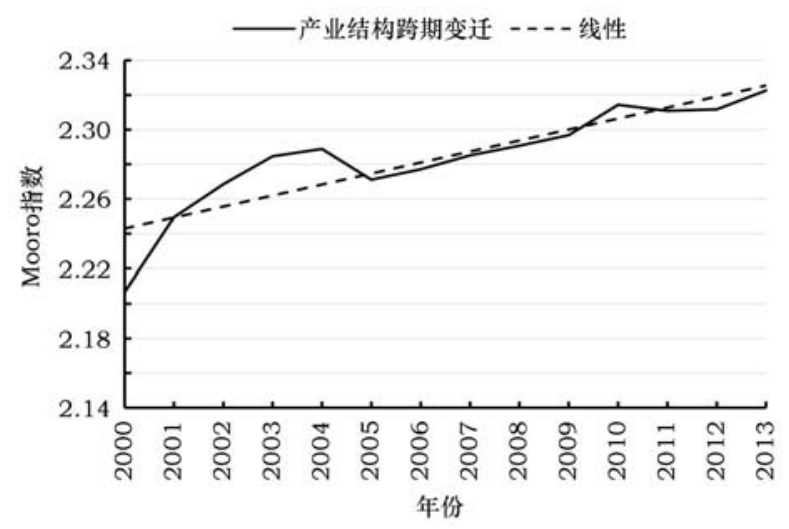

图 1 2000-2013 年中国产业结构的动态跨期变迁

Figure 1 Dynamic intertemporal change of China's industrial structure from 2000 to 2013

表 $12000-2013$ 年中国省际产业结构跨期变迁 Moore 值

Table 1 Moore value of intertemporal change of provincial industrial structure in China from 2000 to 2013

\begin{tabular}{|c|c|c|c|c|c|c|c|c|}
\hline 省份 & 2000年 & 2002年 & 2004年 & 2006年 & 2008年 & 2010年 & 2012年 & 2013年 \\
\hline 北京 & 2.5241 & 2.6492 & 2.6690 & 2.6769 & 2.7088 & 2.7455 & 2.7523 & 2.7561 \\
\hline 天津 & 2.4106 & 2.4182 & 2.4102 & 2.3840 & 2.3823 & 2.4355 & 2.4473 & 2.4563 \\
\hline 河北 & 2.1560 & 2.1796 & 2.1977 & 2.1839 & 2.2081 & 2.2240 & 2.2274 & 2.2332 \\
\hline 山西 & 2.2772 & 2.3595 & 2.3349 & 2.3110 & 2.3050 & 2.3261 & 2.2926 & 2.3284 \\
\hline 内蒙古 & 2.1321 & 2.1982 & 2.2431 & 2.2407 & 2.2310 & 2.2831 & 2.2583 & 2.2630 \\
\hline 辽宁 & 2.2699 & 2.2986 & 2.3111 & 2.2854 & 2.2630 & 2.2934 & 2.2804 & 2.2939 \\
\hline 吉林 & 2.0829 & 2.2120 & 2.2201 & 2.2174 & 2.2346 & 2.2422 & 2.2273 & 2.2292 \\
\hline 黑龙江 & 2.1915 & 2.2193 & 2.2370 & 2.2124 & 2.2178 & 2.2567 & 2.2188 & 2.2489 \\
\hline 上海 & 2.4747 & 2.5087 & 2.4964 & 2.4960 & 2.5147 & 2.5850 & 2.5727 & 2.5975 \\
\hline 江苏 & 2.2299 & 2.2495 & 2.2671 & 2.2745 & 2.3029 & 2.3292 & 2.3617 & 2.3715 \\
\hline 浙江 & 2.2223 & 2.2902 & 2.3267 & 2.3338 & 2.3546 & 2.3808 & 2.3893 & 2.4040 \\
\hline 安徽 & 2.0332 & 2.1441 & 2.2265 & 2.2267 & 2.2254 & 2.2132 & 2.1935 & 2.2004 \\
\hline 福建 & 2.2211 & 2.2372 & 2.2519 & 2.2566 & 2.2914 & 2.3151 & 2.2999 & 2.3025 \\
\hline 江西 & 2.1371 & 2.1726 & 2.1707 & 2.1678 & 2.1534 & 2.1998 & 2.2159 & 2.2290 \\
\hline 山东 & 2.1973 & 2.2087 & 2.2162 & 2.2138 & 2.2377 & 2.2512 & 2.2946 & 2.3138 \\
\hline 河南 & 2.0561 & 2.1000 & 2.1668 & 2.1214 & 2.1521 & 2.1504 & 2.1660 & 2.1818 \\
\hline 湖北 & 2.1554 & 2.2373 & 2.2527 & 2.2368 & 2.2700 & 2.2561 & 2.2383 & 2.2405 \\
\hline 湖南 & 2.1384 & 2.1999 & 2.2367 & 2.2093 & 2.2205 & 2.2618 & 2.2425 & 2.2542 \\
\hline 广东 & 2.2458 & 2.3782 & 2.3850 & 2.3652 & 2.3778 & 2.4062 & 2.4024 & 2.4144 \\
\hline 广西 & 2.0905 & 2.1677 & 2.1874 & 2.1810 & 2.1740 & 2.1858 & 2.1661 & 2.1873 \\
\hline 海南 & 2.0145 & 2.0925 & 2.0714 & 2.0801 & 2.1108 & 2.1727 & 2.1937 & 2.2196 \\
\hline 重庆 & 2.2307 & 2.2760 & 2.2957 & 2.2872 & 2.2977 & 2.2852 & 2.2751 & 2.3105 \\
\hline 四川 & 2.1219 & 2.1765 & 2.1981 & 2.1828 & 2.1707 & 2.2076 & 2.1914 & 2.2070 \\
\hline 贵州 & 2.0541 & 2.1328 & 2.1819 & 2.2092 & 2.2508 & 2.3410 & 2.3603 & 2.3484 \\
\hline 云南 & 2.1438 & 2.1782 & 2.2029 & 2.2013 & 2.2142 & 2.2342 & 2.2575 & 2.2502 \\
\hline 陕西 & 2.2521 & 2.3005 & 2.2929 & 2.2574 & 2.2399 & 2.2871 & 2.2505 & 2.2518 \\
\hline 甘肃 & 2.1654 & 2.2232 & 2.2509 & 2.2469 & 2.2408 & 2.2531 & 2.2556 & 2.2633 \\
\hline 青海 & 2.2553 & 2.2849 & 2.3101 & 2.2711 & 2.2536 & 2.2683 & 2.2304 & 2.2362 \\
\hline 宁夏 & 2.2433 & 2.3029 & 2.3130 & 2.2965 & 2.2714 & 2.3225 & 2.3222 & 2.3345 \\
\hline 新疆 & 2.1750 & 2.2284 & 2.1785 & 2.1596 & 2.1743 & 2.1884 & 2.1660 & 2.1837 \\
\hline
\end{tabular}

注:仅列出部分年份省际产业结构跨期变迁值,其余年份备索。由于数据缺失,西藏、香港、澳门、台湾除外。 
看, 中国产业结构变迁 Moore 值从 2000 年的 2.207 , 上升到 2013 年的 2.323 ,期间提高了约 $5.26 \%$ 。

\subsection{2 产业结构变迁与旅游业发展}

产业结构变迁主要从供需两方面对旅游业产 生影响。从需求方面看,在一个经济体中,如果不 同部门并非按照等边际原则配置生产要素, 产业结 构变迁即意味着资本和劳动力要素在不同部门之 间重新配置,便会促进生产率的集约式增长,进而 会决定经济增长的规模和方式,再进一步影响旅游 业潜在客源市场的可支配收人与消费意识, 前者刺 激了旅游产品消费规模, 而后者关涉到旅游产品消 费结构, 即产业结构变迁最终会从需求规模和结构 两方面影响旅游业发展。在供给方面,可从如下三 点进行考虑:

（1）产业结构变迁改变了中国旅游业发展模 式,在工业化阶段,主要以要素资源驱动式的大众 观光旅游为主, 而随着服务业经济时代到来, 以技 术进步驱动的体验式休闲度假成为旅游业发展模 式的转变方向。

(2)中国旅游业现阶段正处于规模报酬递增阶 段,作为现代服务业的重要组成部分,产业结构变 迁的资源配置效应使得劳动、资本、技术等生产要 素开始向旅游部门转移、流动和集聚, 从而为旅游 业发展提供了重要源泉。

（3）产业结构变迁重塑旅游产品体系,尤其是 现代服务业的发展,为旅游产业融合创造了优越条 件, 随即出现了有别于旅游业内部传统单项产品 (旅游景区、旅行社、星级酒店、旅游车船)之外,形 式新颖、类型丰富以及功能多样的购物娱乐、商务 会奖以及文化体验等旅游消费弹性较高的休闲度 假产品, 以此拓展旅游者的扩展性旅游消费支出, 从而最终会增强旅游业的收人效应。

由图 2 可以看出, 《中国旅游年鉴》[17]数据显示, 在中国历年旅游总收人中, 除了旅游者在旅游景 区、旅行社、星级酒店和旅游车船公司四类基本旅 游企业的旅游消费支出之外，以购物、娱乐等为代 表性的扩展旅游消费支出的比例基本呈线性增长 趋势, 并且基本与产业结构变迁动态趋势一致 （2003年非典事件除外）。与此同时,旅游者扩展旅 游消费支出所创造的收人在旅游总收人中占比已

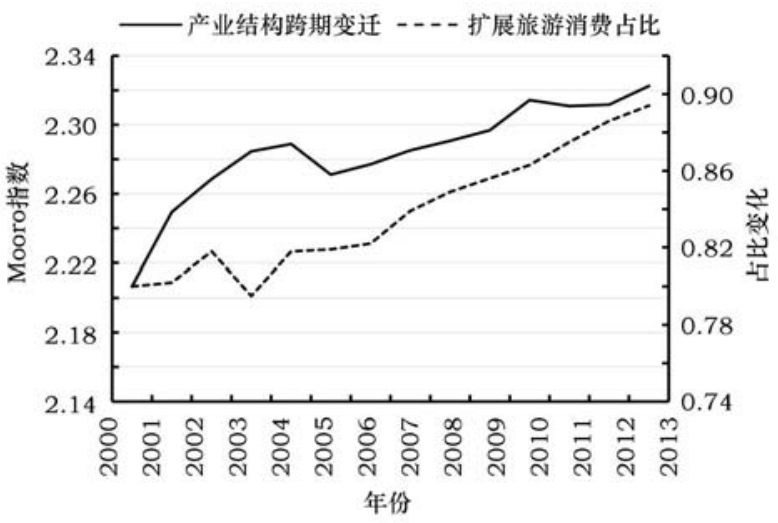

图 $22000-2013$ 年中国产业结构跨期变迁 与扩展旅游消费占比

Figure 2 Intertemporal change of industrial structure and ratio of expanding tourist consumption in China from 2000 to 2013

近 90\%，而旅游消费“食、住、行、游”四个基本旅游 要素方面的支出比例日渐下降,这也充分说明产业 结构变迁对旅游业要素资源的配置效应, 从产品创 新方面内生驱动了旅游业发展。

2.1.3 产业结构变迁与旅游业经济贡献率

从中国产业结构变迁的方向来看,产业结构优 化升级的主要目标是以现代制造业为驱动, 现代服 务业为主导, 前者是经济增长的基础, 后者是经济 增长的动力。值得关注的是, 旅游业作为现代服务 业的重要组成部分,因产业结构变迁而引发的要素 资源配置所产生的“结构效应”, 显著扩大了旅游业 生产要素的投入规模, 从而为驱动旅游业发展提供 了必不可少的基本增长因素。更重要的是,技术要 素的流人,不仅直接推动了旅游业的技术进步,使 得旅游业生产率得以提升,旅游业因此获得发展的 “结构红利”, 而且由此所驱动的旅游业规模扩张, 又可通过对上下游关联产业的波及效应, 为经济增 长注人新的活力, 又会提高旅游业对经济增长的绝 对贡献率，而且更因为技术进步主导旅游业发展方 式转型, 使得旅游业开始向知识密集型转变, 由此 而产生的旅游业发展质量的改善, 反之又实现了其 在规模扩张基础上的可持续发展,最终又进一步保 障了旅游业对经济增长的持续贡献率。以上阐述 的是, 由产业结构变迁驱动旅游业发展而对经济增 长作用产生的整体贡献。事实上, 在具体的微观影 响机制上,作为现代新兴产业部门,旅游业还可以 弥补以工业化为主导的经济结构所固有的诸多弊 
端, 例如,在工业化时代,依靠要素资源粗放开发所 驱动的传统城镇化模式愈发不可持续, 而旅游业引 导的新型城镇化进程有力地提高了城镇化质量。 再如, $\mathrm{k}$ 国居民消费率近年来持续走低已成不争事 实, 而随着人们旅游消费意识地逐渐转变, 旅游业 在刺激居民消费率方面贡献显著。因此,旅游业所 表现出的以上特殊作用,在广义上有益于平衡经济 结构体系。

不仅如此,在经济服务化和新型工业化作为中 国产业结构变迁主要目标的条件下, 新型工业化与 现代旅游业之间也并非相互矛盾, 而是彼此相互促 进,成为推动经济增长的重要力量。从产业关联角 度分析, 新型工业化发展在很大程度上决定了现代 服务业的需求规模和产品结构,尤其是 “以人为本” 的现代企业经营管理理念愈加重视员工的精神层 面建设,所以,以现代商务、会奖旅游为标志的新兴 旅游业态, 作为闲暇时间的一种利用形式, 因其对 技术进步产生正外部性而有助于人力资本形成, 进 而对企业员工劳动生产率具有提升效应, 最终在整 体上有利于经济增长 ${ }^{[18,19]}$ 。新型工业化要求现代旅 游业所内涵的此种“生产性”服务业特点,进一步扩 大了旅游业的消费对象，拓宽了旅游产品的消费空 间,并且在一定程度上反而又促进了新型工业化的 发展, 从而也会间接提高旅游业对经济增长的贡献 率。综上,结合图 3 可知,除个别年份由于外部环境 因素影响导致旅游业经济贡献率出现奇异值之外 (非典、金融危机、汇率升值),旅游业经济贡献率与

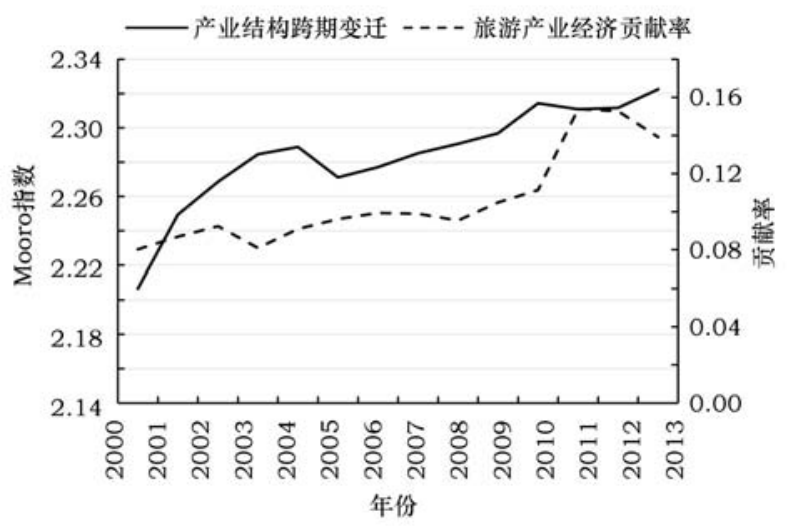

图 $32000-2013$ 年中国产业结构跨期变迁 与旅游业经济贡献率变化

Figure 3 Intertemporal change of industrial structure and contribution rate of tourism to economy in China from 2000 to 2013
产业结构跨期变迁的变化趋势也基本具有一致性, 这也反映出两者之间所存在的正相关关系。

\section{2 理论分析}

当前, 经济增长方式倒逼产业结构转型、优化 与升级,中国社会因此正经历全面而又深刻的产业 结构变迁过程, 而由此所驱动的生产率改善与提 升,作为一种普遍的宏观经济变动规律,均在供需 两端决定了对旅游业发展的影响。然而,对此理论 思想的应然研究却较为鲜见。因此, 本文主要关切 的理论命题是:产业结构变迁因素在旅游业对经济 增长的影响过程中是否具有调节效应。

针对该理论命题,在上文对产业结构变迁与旅 游业关系的基本事实进行初步判断时,已展开了相 应的理论叙述。从动态的视角审视,产业结构变迁 是指经济体的产业结构由低级向高级的规律性演 变过程,主要包括产业结构合理化和产业结构高级 化两个演进维度。前者是指要素资源在部门之间 配置所产生的结构协调与经济均衡效应; 后者是指 要素资源在效率差异部门之间流动所导致的产业 升级和生产率提升效应。具言之, 旅游业作为新兴 产业部门,产业结构合理化可以高效地配置有助于 旅游业发展所必需的要素资源, 从而持续增强旅游 业边际生产力, 同时凭借其显著的产业关联效应, 促使要素资源在跨产业间流动, 同时在以满足消费 者综合性体验需求为导向的旅游产品生产理念下， 要素资源的市场配置效应推动了产业结构的均衡 协调。旅游业作为“经济结构服务化”的典型行业, 产业结构高级化为旅游业跨越式发展提供了关键 技术要素, 不仅有助于旅游业实施创新驱动战略, 进而创造旅游业价值链增值, 更重要的是, 可以推 动旅游业经济增长方式转变, 进而有助于实现旅游 业发展质量的提升, 尤其是随着技术进步驱动以效 率为主导的旅游业规模扩张, 在上述影响机制下, 旅游业对经济增长的贡献率得以显著增强。

如果深人到上述理论机制内部,旅游业的经济 增长效应亦会表现出基于产业结构变迁的变化特 征, 即随着产业结构的动态变迁, 旅游业的经济增 长效应亦会发生相应变化。正如2.1.2 章节,旅游业 的发展对产业结构调整具有敏感性,产业结构的转 型与升级,势必会影响旅游业发展的规模与质量, 
从而导致旅游业的经济增长效应并非简单线性。 而由图 3 所示,产业结构跨期变迁与旅游业经济贡 献率两者波动变化趋势的近似一致性,也为基于产 业结构变迁的旅游业对经济增长影响过程的调节 效应提供了事实佐证。然而,产业结构变迁并非一 直会对旅游业影响经济增长机制具有正向调节作 用。譬如,一方面,倘若要素资源在产业部门间错 配而导致产业结构不合理, 从而限制了旅游业扩张 所需的要素资源,也会抑制旅游业对经济增长的贡 献。另一方面, 旅游业作为服务业主要门类, 特别 是以劳动密集型为主的传统旅游业, 其生产率要低 于工业制造业，而由于工业化所面临的资源和环境 的双重约束, 经济结构在服务化倾向过程中,要素 资源则从生产率相对较高的制造业部门转移到生 产率相对较低的传统服务业部门,从而会导致要素 资源在旅游业部门的配置效率下降,进而从全社会 层面上抑制了生产率的提升(图 4)。

\section{3 模型、变量和数据}

\section{1 模型设定}

基于上述理论阐释,需将产业结构变迁因素纳 人到中国 TLG 假说检验的实证框架, 首先检验旅游 业和产业结构变迁对经济增长的影响, 然后再构建 旅游业与产业结构变迁的交互项, 以便考察产业结 构变迁是否会对旅游业的经济增长效应具有调节 作用,故设定如下形式的面板数据模型：

$$
\begin{aligned}
\ln \text { growth }_{i t}= & \alpha+\beta T O U R_{i t}+\xi I N D_{i t} \\
& +\psi T O U R_{i t} \times I N D_{i t}+X_{i t} \delta+\mu_{i}+\varepsilon_{i t}
\end{aligned}
$$

式中 growth $h_{i t}$ 为被解释变量, 即省份 $i$ 在 $t$ 期的经济 增长水平; TOUR $R_{i t}$ 和 $I N D_{i t}$ 则分别表示省份 $i$ 在 $t$ 期 的旅游业发展和产业结构变迁水平,下标 $i$ 和 $t$ 分别 为省份和年份; $X$ 为控制变量集,包括投资份额、人
力资本、政府规模、贸易开放、制度环境和城镇化; 为截距项； $\alpha 、 \beta 、 \psi$ 和 $\delta$ 分别为旅游业、产业结构 变迁、旅游业与产业结构变迁乘积项以及控制变量 的估计系数; $\mu_{i}$ 为非观测的不随时间变化的个体因 素; $\varepsilon_{i t}$ 为随机误差项。

由于产业结构变迁具有两个基本的动态维度, 即产业结构合理化 $\left(T L_{i t}\right)$ 和产业结构高级化 $\left(T S_{i t}\right)$, 同时为了检验旅游业与产业结构变迁之间的交互 作用,需在公式(3)中同时予以体现,所以模型分别 拓展为:

$$
\begin{aligned}
\ln \text { growth }_{i t}= & \alpha+\beta T O U R_{i t}+\xi_{1} T L_{i t} \\
& +\psi_{1} \text { TOUR }_{i t} \times T L_{i t}+X_{i t} \delta+\mu_{i}+\varepsilon_{i t} \\
\ln \text { growth }_{i t}= & \alpha+\beta T O U R_{i t}+\xi_{2} T S_{i t} \\
& +\psi_{2} \text { TOUR }_{i t} \times T S_{i t}+X_{i t} \delta+\mu_{i}+\varepsilon_{i t}
\end{aligned}
$$

\section{2 变量度量}

\subsection{1 旅游业发展}

对旅游业发展的测度,主要分为收人和人次两 个度量指标, 即旅游专业化和旅游人次比, 具体分 别以旅游业总收人占国内生产总值比值 ${ }^{[20,21]}$ 和旅游 人次占总人口比值度量 ${ }^{[22,23]}$ 。然而, 直于国内旅游 人次存在着重复统计问题,很可能会因此高估旅游 业的真实水平,而旅游业对经济增长的收人效应直 接反映出其对经济增长的贡献强度,所以本文采用 收人指标来度量地区旅游业发展水平, 这与赵磊和 Chang 等的研究保持一致 ${ }^{[10,24]}$ 。

\subsection{2 产业结构变迁}

（1）产业结构合理化。产业结构合理化的目标 是实现要素资源在产业间优化配置, 以使产业相互 协调发展。因此,一般采用结构偏离度对产业结构 合理化进行度量,测度公式为:

$$
E=\sum_{i=1}^{n}\left|\frac{Y_{i} / L_{i}}{Y / L}-1\right|=\sum_{i=1}^{n}\left|\frac{Y_{i} / L_{i}}{L_{i} / L}-1\right|
$$

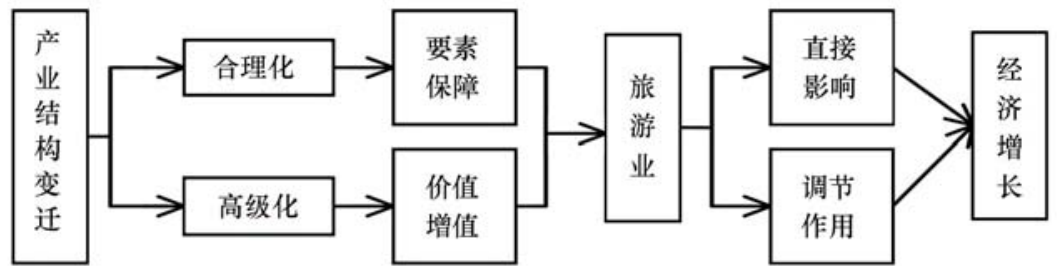

图 4 产业结构变迁在旅游业影响经济增长中的调节机制

Figure 4 Moderatoring mechanism of change of industrial structure for the effect of tourism on economic growth 
式中 $E$ 产业结构偏离度; $Y$ 为产值; $L$ 为就业人数; $i$ 为产业; $n$ 为产业部门数。依据古典经济学假设,经 济体若最终处于均衡状态, 各产业部门生产率水平 应相同。定义 $Y / L$ 为生产率, 当经济体处于均衡状 态时, 各产业部门生产率与经济体总生产率水平相 等, 即 $Y_{i} / L_{i}=Y / L, E=0$ 。同时, $E$ 表示经济体偏离 均衡状态的程度; $E$ 值越大, 表示经济体偏离均衡 状态的程度越大, 即产业结构越不合理。实质而 言, 经济体很难实现其理想均衡状态, 而经济非均 衡则是一种普遍常态,这一经济现象尤其在发展中 国家表现异常突出 ${ }^{[25]}$,也即 $E \neq 0$ 。然而,需要注意 的是, 产业结构的此种偏离度测量指标具有商榷之 处, 即忽略了产业部门在经济体中的相对重要地 位,因而存在较大测量偏差。

为克服上述弊端, 可以参照干春晖等的做法 ${ }^{[26]}$, 采用测度区域经济发展差距的泰尔指数 (Theil index)来度量产业结构合理化指标。相应公式为：

$$
T L=\sum_{i=1}^{n}\left(\frac{Y_{i}}{Y}\right) \ln \left(\frac{Y_{i}}{L_{i}} / \frac{Y}{L}\right)
$$

相似地, 若经济体处于均衡状态, 则 $T L=0$, 该 指数不仅兼顾了相关产业部门在国民经济中的相 对重要性,同时亦保留了产业结构偏离度的理论内 涵和经济意义,而若 $T L \neq 0$, 则表明产业结构不合 理,偏离均衡状态。

（2）产业结构高级化。产业结构高级化是产业 结构升级的一种衡量形式,表现为产业结构由低级 到高级的动态变迁。为此,本文遵循付凌晖的测度 方式 ${ }^{[27]}$, 以三次产业部门增加值占比与其所对应坐 标体系夹角的变化来度量产业高级化指标。定义 夹角计算公式为:

$$
\begin{gathered}
\theta_{j}=\arccos \left[\frac{\sum_{i=1}^{\alpha} x_{i, j} \times x_{i, 0}}{\sqrt{\sum_{i=1}^{\alpha} x_{i, j}^{2} \times \sqrt{\sum_{i=1}^{\alpha} x_{i, 0}^{2}}}}\right] \\
(\alpha=1,2,3 ; j=1,2,3)
\end{gathered}
$$

式中 $\theta_{j}$ 为第 $j$ 个产业部门增加值占国内生产总值比 值与所对应坐标体系夹角; $x_{i}$ 为产业部门增加值占 国内生产总值比值; 以每一产业部门增加值占比作 为空间向量的一个分量, 从而构建一组三维向量
$X_{0}=\left(x_{1,0}, x_{2,0}, x_{3,0}\right)$, 依次分别计算 $X_{0}$ 与产业部门由 低层次到高层次排列的向量 $X_{1}=(1,0,0)$, $X_{2}=(0,1,0), X_{3}=(0,0,1)$ 的夹角 $\theta_{1} 、 \theta_{2}$ 和 $\theta_{3}$, 定义三 次产业综合转移效应 $T S=\pi-\theta_{2}-\theta_{3}$, 其值越大, 表 示产业部门之间综合转移水平越高。

\subsection{3 控制变量}

控制变量包括:

(1) 投资份额 (Invest)。根据新古典经济学理 论, 资本投资是驱动经济增长的重要内生源泉, 采 用资本形成总额与国内生产总值比值度量。

(2) 人力资本 (Human)。内生经济增长理论指 出, 人力资本对技术创新存在显著的溢出效应, 因 而成为经济增长的重要决定因素, 采用劳动力人均 受教育年限度量。

(3) 政府规模 (Govern)。政府“干预”行为在经 济活动中具有重要作用,采用采用政府支出占国内 生产总值比值度量。

(4) 贸易开放 (Trade)。出口贸易有效拓宽了国 内产品市场需求规模,采用进出口贸易总额占国内 生产总值比值度量。

(5)制度环境(Institution)。制度环境是决定长 期经济绩效的基本因素,采用非国有企业职工所占 比例度量。

(6) 城镇化 (Urban)。城镇化为经济增长提供 了必要的供需条件, 采用城镇人口占总人口比值 度量。

\section{3 数据来源}

考虑到数据可得性与一致性, 本文采用 19992013 年中国大陆 30 个省、市、自治区省级面板数 据, 由于数据获取困难, 本次研究不包括香港、台 湾、澳门和西藏。其中, 旅游业数据来源于《中国旅 游年鉴 (2000-2014) $\rangle^{[16]}$, 其他原始数据分别来源于 《中国统计年鉴(2000-2014) 》[17]。

\section{4 结果及分析}

\section{1 旅游业对经济增长的影响}

使用 1999-2013 年省级平衡面板数据对公式 (4)、公式 (5) 的回归结果如表 2 所示。为了对比分 析, 模型 (1) 和模型 (2) 是对公式(4)、公式(5)在未 纳人旅游业和产业结构变迁的交互项之前的回归 
表 2 模型估计结果

Table 2 Estimated results of model

\begin{tabular}{|c|c|c|c|c|}
\hline 变量 & 模型(1) & 模型(2) & 模型(3) & 模型(4) \\
\hline TOUR & $1.090 * * *(0.166)$ & $1.089 * * *(0.167)$ & $0.545^{*} \quad(0.291)$ & $0.851 * *(0.845)$ \\
\hline$T L$ & $0.208 * * *(0.068)$ & - & $0.034 \quad(0.102)$ & - \\
\hline$T O U R \times T L$ & - & - & $1.598 * *(0.703)$ & - \\
\hline$T S$ & - & $0.372 * * *(0.140)$ & - & $0.641 * * *(0.212)$ \\
\hline$T O U R \times T S$ & - & - & - & $0.139 * \quad(0.871)$ \\
\hline Invest & $0.335 * * *(0.035)$ & $0.300 * * *(0.037)$ & $0.349 * * *(0.035)$ & $0.293 * * *(0.037)$ \\
\hline Human & $0.027 * *(0.012)$ & $0.028 * *(0.012)$ & $0.028 * *(0.012)$ & $0.026 * *(0.012)$ \\
\hline Govern & $0.700 * * *(0.115)$ & $0.651 * * *(0.116)$ & $0.629 * * *(0.119)$ & $0.671 * * *(0.117)$ \\
\hline Trade & $0.031 \quad(0.031)$ & $0.027 \quad(0.031)$ & $0.033 \quad(0.031)$ & $(0.031)$ \\
\hline Institution & $0.188 * *(0.074)$ & $0.106 \quad(0.071)$ & $0.165 * * \quad(0.74)$ & $(0.071)$ \\
\hline Urban & $0.184 * *(0.058)$ & $0.176 * * *(0.058)$ & $0.200 * * *(0.058)$ & $0.198 * * *(0.059)$ \\
\hline 省份效应 & 控制 & 控制 & 控制 & 控制 \\
\hline$F$ 统计量 & $103.89 * * *$ & $99.13 * * *$ & $103.76^{* * *}$ & $96.11 * * *$ \\
\hline$R^{2}$ & 0.824 & 0.824 & 0.826 & 0.824 \\
\hline 样本量 & 450 & 450 & 450 & 450 \\
\hline
\end{tabular}

注: ***、**和*分别表示 $1 \% 、 5 \%$ 和 10\%显著性水平; 括号内为标准差。

结果,模型 (3) 和模型 (4) 是对公式(4)、公式 (5) 的 回归结果。模型 (1) 和模型 (2) 显示旅游业估计系 数在 $1 \%$ 水平上显著为正,而模型 (3) 和模型 (4)分 别显示旅游业估计系数在 $10 \%$ 和 $5 \%$ 水平上显著为 正, 由此说明中国旅游业发展对经济增长具有显著 的积极影响, 即 TLG 假说在中国具有真实性, 从而 为中国实施旅游业促进经济增长的产业发展战略 提供了经验依据。从理论上分析,旅游业对经济增 长的直接影响机制表现在旅游业可以为地区经济 增长提供外汇收人、创造就业岗位和增加税收收 人,间接影响机制表现在旅游业可以通过对其关联 产业的间接诱导效应带动经济增长。

\section{2 产业结构变迁对经济增长的影响}

模型 (1) 回归结果显示, 产业结构合理化估计 系数在 $1 \%$ 显著性水平上为正,鉴于产业结构合理 化指标测度的反向性, 表明产业结构合理化对经济 增长具有一定的抑制作用。究其原因,由于中国要 素市场化滞后,使得要素无法按照市场机制进行合 理配置, 从而产生要素市场的扭曲, 直接导致要素 在经济产业部门间发生错配,由此所引发的产业结 构不合理的非均衡效应会对经济增长产生显著负 向影响,进而也有力地验证了现阶段中国要素市场 存在“扭曲配置”而诱发经济负面影响的学术观点 ${ }^{[28,29]}$
对此公认的一个合理解释是, 由于受到诸多来自于 制度方面的约束,在要素市场扭曲的情形下,生产 要素无法遵循市场机制实现在产业间最优配置,进 而导致生产要素在产业间配置效率低下, 由此加剧 的产业结构不合理现象,势必对经济体的全要素生 产率产生负面影响,进而最终会抑制经济增长 ${ }^{[30]}$ 。

模型 (2) 回归结果报告出另一产业结构变迁的 重要维度, 即产业结构高级化估计系数也通过了 $1 \%$ 水平的显著性检验, 并且符号为正, 说明产业结 构高级化对经济增长具有显著积极影响, 由于产业 结构高级化反映出要素资源在效率差异部门之间 流动时, 可以实现要素资源在产业升级演进中的优 化配置, 因而有效提升了总体全要素生产率水平, 所以上述的产业结构素质的提升过程所产生的“结 构红利” 直接促进了经济增长。从理论上分析, 产 业结构高级化对经济增长的影响路径可概括为三 个方面。其一,产业结构的高技术效应。由技术进 步推动的产业升级,不仅可以提高新兴产业及现代 服务业的边际生产力, 同时也极大改善了传统产业 的劳动生产率。其二,产业结构的高信息效应。现 代信息技术的应用,可以有效提高市场经营主体的 管理水平和经营绩效,进而可以增强对要素资源的 利用效率。其三,产业结构的高集约效应。产业结 
构在高级化演进时, 同时还伴随着产业组织的合理 化，进而有助于促进产业间实现专业化分工协作， 并产生规模经济效益,由此使得生产效率得以提 升。综上,产业结构高级化是保持经济持续增长的 重要源泉。

综上所述,产业结构高级化对经济增长具有促 进作用，而产业结构合理化则对经济增长具有抑制 作用, 尤其是前者系数绝对值大于后者, 说明产业 结构高级化对经济增长的“升级效应”要大于产业 结构合理化对经济增长的“扭曲效应”,产业结构升 级对全要素生产率的提升效应弥补了产业结构转 型所引致的效率损失, 成为中国经济增长的动力。 本文对此的研究发现并不同于干春辉等和于斌斌 的研究结论 ${ }^{[26,31]}$, 尤其是后者的立场为 “中国产业结 构并非具有服务趋向的高级化,无法支撑经济的高 速增长”。本文对此类论点的质疑之处在于, 由于 其对产业结构高级化的测度仅是简单采用二、三产 业的产值比重衡量, 从而主观抹杀了包括农业在内 的三次产业的综合转移效应,尤其是忽视了农业要 素资源向二、三产业的转移效应, 从而导致出现以 局部而表征全局的狭险视域。此外,本文的研究发 现正说明,要素资源向高效率部门配置, 即产业结 构的服务化倾向所引发的生产率提升效应是推动 中国经济增长的重要机制。

\section{3 旅游业与产业结构变迁交互项对经济增长的 影响}

为揭示产业结构变迁因素对旅游业影响经济 增长过程的作用机制, 分别对产业结构合理化和高 级化与旅游业的交互效应予以检验。

模型 (3) 回归结果报告出旅游业与产业结构合 理化交互项估计系数在 $5 \%$ 水平上正向显著,说明 在当前产业结构合理化水平较低的情形下,在对经 济增长影响方面,旅游业和产业结构合理化之间具 有一定程度的替代效应。换言之,当要素资源在产 业部门间误置时, 由于恶化了产业部门间协调发展 状态, 导致要素资源无法流人规模报酬递增的新兴 部门,如旅游业, 而旅游业供给侧对经济增长的贡 献主要来源于旅游业产品供给形式的多样化,正是 由于旅游业缺乏来自于多元化要素资源的有效配 置, 从而抑制了旅游业对经济增长的积极贡献。
模型 (4) 回归结果报告出旅游业与产业结构高 级化交互项估计系数显著为正, 并在 $10 \%$ 水平上具 有统计意义,意指产业结构高级化正向调节旅游业 对经济增长的影响作用,旅游业和产业结构高级化 之间具有一定程度的互补效应,抑或理解为旅游业 也会加强产业结构高级化对经济增长的积极影 响。旅游业作为典型的现代新兴服务业部门,其对 经济增长的促进作用势必离不开产业结构的服务 化升级, 即产业结构高级化对旅游业的经济增长效 应具有积极的溢出效能。因此,推动产业结构高级 化以增强旅游业对经济增长的积极效应是揭示旅 游导向型经济增长模式的创新视角。

\section{5 结论及政策含义}

本文研究表明:

(1) 旅游业估计系数显著为正, 表明旅游业是 促进中国经济增长的动力因子之一, 中国存在 TLG 假说。

(2)在样本期内, 以泰尔指数反向度量的产业 结构合理化对经济增长存在抑制作用,而产业结构 高级化则对经济增长具有积极作用, 同时产业结构 高级化对经济增长的积极 “结构效应”要大于产业 结构合理化对经济增长的负面“失衡效应”。

（3）以泰尔指数反向度量的产业结构合理化负 向调节旅游业影响经济增长效应, 而产业结构高级 化正向调节旅游业影响经济增长效应。

本文的边际学术贡献包括两个方面：

(1)深人地推进了国内外关于 TLG 假说的实证 研究框架, 这不仅有利于进一步客观揭示旅游业对 经济增长的影响效应和机制, 更重要的是, 在面临 地区经济结构转型的宏观背景下,可以为地方政府 提供旅游业作为刺激地区经济增长的战略工具选 择。这一学术贡献, 是对 Pablo-Romero 等关于西方 TLG 假说述评性研究的回应和延伸 ${ }^{[32]}$ 。

(2)拓展和深化了关于产业结构变迁和经济增 长之间关系的研究框架, 既有研究主要是将生产性 服务业中的金融、信息和研发等行业纳人其中,以 探讨在产业结构变迁的影响下，上述细分服务行业 与经济增长之间的关系 ${ }^{[33-35]}$, 而本文首次将旅游业 引人上述研究框架, 从而丰富了该领域的研究 内容。 
本文研究结论形成如下政策性启示：

(1) 可继续实施旅游业导向型经济增长战略, 旅游业对经济增长的积极贡献值得信赖。

（2)政府在推进产业结构调整时,除了应着重 强调产业结构高级化的同时,还需高度关注产业结 构合理化,由此即可以通过产业结构升级提升全要 生产率,还可以减缓由要素资源在产业部门间的错 配而导致产业结构合理化对经济增长的抑制效应, 所以要尽可能实现要素资源的均衡流动和产业部 门之间的协调发展。

（3）产业结构在服务化升级过程中,现代性服 务业部门应需探索、创造与旅游业的融合发展机 制，强化其知识、技术和服务优势对旅游业的溢出 功能, 进而扩大创新培育新型旅游产品业态的增量 优势。除此之外,继续推进产业结构合理化,依靠 市场调节机制来缓解要素资源的扭曲错配, 鼓励、 引导要素资源在产业部门间均衡配置, 实现产业部 门间协调发展, 从而为提升旅游产品组织效率, 健 全旅游产品体系创造要素保障。

\section{参考文献(References) :}

[1] Chow G, Lin A. Accounting for economic growth in Taiwan and Mainland China: a comparative analysis[J]. Journal of Comparative Economics, 2002, 30(3):507-530.

[2] Wang Y, Yao Y. Sources of China's economic growth 1952-1999: incorporating human capital accumulation[J]. China Economic Review, 2003, 14(1):32-52.

[3] Zhang C, Zhuang L. The composition of human capital and economic growth: evidence from China using dynamic panel data analysis[J]. China Economic Review, 2011, 22(1): 165-171.

[4] Zhu X. Understanding China's growth: past, present, and future [J]. The Journal of Economic Perspectives, 2012, 26 (4) : 103124.

[5] Chenery H B, Robinson S, Syrquin M. Industrialization and Growth: a Comparative Study[M]. London: Oxford University Press, 1986.

[6] Akinboade $\mathrm{O}$ A, Braimoh L A. International tourism and economic development in South Africa: a granger causality test[J] International Journal of Tourism Research, 2010, 12 (2) : 149163.

[ 7 ] Fayissa B, Nsiah C, Tadesse B. Tourism and economic growth in Latin American countries-further empirical evidence[J]. Tourism
Economics, 2011, 17(6): 1365-1373

[ 8 ] Hye Q M A, Khan R E A. Tourism-led growth hypothesis: a case study of Pakistan[J]. Asia Pacific Journal of Tourism Research, 2013, 18(4): 303-313

[9] Tang C F, Abosedra S. The impacts of tourism, energy consumption and political instability on economic growth in the MENA countries[J]. Energy Policy, 2014, 68: 458-464.

[10] 赵否. 旅游发展与经济增长-来自中国的经验证据[J]. 旅游学 刊, 2015, 30(4): 33-49. [Zhao L. Tourism development and economic growth: Empirical evidence from China[J]. Tourism Tribune, 2015, 30(4): 33-49.]

[11] Adams P D, Parmenter B R. An applied general equilibrium analysis of the economic effects of tourism in a quite small, quite open economy[J]. Applied Economics, 1995, 27 (10): 985994.

[12] 林毅夫, 章奇, 刘明兴. 金融结构与经济增长: 以制造业为例 [J]. 世界经济, 2003, (1): 3-21. [Lin Y F, Zhang Q, Liu M X Financial structure and economic growth: the case of manufacturing industry[J]. The Journal of World Economy, 2003, (1): 3-21.]

[13] 韩永辉, 黄亮雄, 邹建华. 中国经济结构性减速时代的来临 [J]. 统计研究, 2016, 33 (5) : 23-33. [Han Y H, Huang L X, Zou J H. The advent of the era of China's economic structural slowdown [J]. Statistical Research, 2016, 33(5):23-33.]

[14] 张勇, 蒲勇健. 产业结构变迁及其对能源强度的影响 [J]. 产业 经济研究, 2015, (2) : 15-22. [Zhang Y, Pu Y J. Industrial structure evolution and its impact on energy intensity[J]. Industrial Economic Research,2015, (2):15-22.]

[15] 孙叶飞, 夏青, 周敏. 新型城镇化发展与产业结构变迁的经济 增长效应 $[\mathrm{J}]$. 数量经济技术经济研究, 2016, 33(11): 23-40, [Sun Y F, Xia Q, Zhou M. The economic growth effects of new urbanization development and industrial structure change[J]. The Journal of Quantitative \& Technical Economics, 2016, 33(11): 23-40.]

[16] 国家统计局. 中国统计年鉴[M]. 北京: 中国统计出版社, 2000 2014. [National Bureau of Statistics of Industry of China. China Industry Statistical Yearbook[M]. Beijing: China Statistics Press, 2000-2014.]

[17] 国家旅游局. 中国旅游年鉴[M]. 北京: 中国旅游出版社, 2000 2014. [China National Tourism Administration. The Yearbook of China Tourism[M]. Beijing: China Tourism Press, 2000-2014.]

[18] Romer P M. Capital, labor and productivity[J]. Brooking Papers on Economic Activity, 1990, 98 (5): 71-102.

[19] Jones C I. Time series tests of endogenous growth models[J]. Quarterly Journal of Economics, 1995, 110(2): 495-525.

[20] Lee C, Chang C. Tourism development and economic growth: a closer look at panels[J]. Tourism Management, 2008, 29(1): 180- 
192.

[21] Adamou A, Clerides O. Prospects and Limits of Tourism-Led Growth: The International Evidence [R]. RCEA Working Paper, 2009.

[22] Kim H, Chen M, Jan S. Tourism expansion and economic development: the case of Taiwan[J]. Tourism Management, 2006, 27(5): 925-933.

[23] Cortés-Jiménez I. Which type of tourism matters to the regional economic growth? The cases of Spain and Italy[J]. International Journal of Tourism Research, 2008, 10(2): 127-139.

[24] Chang C L, Khamkaew T, McAleer M. IV estimation of a panel threshold model of tourism specialization and economic development [J]. Tourism Economics, 2012, 18(1): 5-41.

[25] Chenery H B, Taylor L. Development patterns: among countries and over time[J]. Review of Economics \& Statistics, 1968, 50 (4):391-416

[26] 干春辉, 郑若谷, 余典范. 中国产业结构变迁对经济增长和波 动的影响 [J]. 经济研究, 2011, (5): 4-16. [Gan C H, Zheng R G, Yu D F. An empirical study on the effects of industrial structure on economic growth and fluctuations in China[J]. Economic Research Journal, 2011, (5): 4-16.]

[27] 付凌晖. 我国产业结构高级化与经济增长关系的实证研究 $[\mathrm{J}]$. 统计研究, 2010,27(8): 79-81. [Fu L H. An empirical research on industry structure and economic growth[J]. Statistical Research, 2010, 27 (8): 79-81.]

[28] 罗德明, 李晔, 史晋川. 要素市场扭曲、资源错置与生产率 [J]. 经济研究, 2012, (3) : 4-14. [Luo D M, Li Y, Shi J C. Factor distortion, misallocation and productivity[J]. Economic Research Journal, 2012, (3): 4-14.]

[29] 袁鹏, 杨洋. 要素市场扭曲与中国经济效率 [J]. 经济评论, 2014, (2) : 28-40. [Yuan P, Yang Y. The distortion of factor market and economic efficiency in China[J]. Economic Review, 2014, (2): 28-40.]

[30] Hsieh C T, Klenow P J. Misallocation and manufacturing TFP in China and India[J]. Quarterly Journal of Economics, 2009, 124 (4): 1403-1448

[31] 于斌斌. 产业结构调整与生产率提升的经济增长效应-基于中 国城市动态空间面板模型的分析 [J]. 中国工业经济, 2015, (12) : 83-98. [Yu B B. Economic growth effects of industrial restructuring and productivity improvement: analysis of dynamic spatial panel model with Chinese city data[J]. China Industrial Economics, 2015, (12): 83-98.]

[32] Pablo-Romero M P, Molina J A. Tourism and economic growth: a review of empirical literature[J]. Tourism Management Perspectives, 2013, 8(1):28-41.

[33] Nelson R R. The co- evolution of technology, industrial structure, and supporting institutions[J]. Industrial and Corporate Change, 1994, 3(1): 47-63.

[34] Rajan R G, Zingales L. Financial systems, industrial structure, and growth[J]. Oxford Review of Economic Policy, 2001, 17(4): 467-482.

[35] Teece D J. Firm organization, industrial structure, and technological innovation[J]. Journal of Economic Behavior \& Organization, 1996,31(2): 193-224. 


\title{
China's tourism industry, industrial structure and economic growth
}

\author{
ZHAO Lei ${ }^{1}$, TANG Chengcai ${ }^{2}$ \\ (1. School of Economics and Management, Zhejiang University of Technology, Hangzhou 310023, China; \\ 2. School of Tourism Management, Beijing International Studies University, Beijing 100024, China)
}

\begin{abstract}
The tourism industry has become a popular sector in regional development. The impact of tourism on economic growth remains a hot issue for government and academia. With China's economy transitioning to a 'new normal', changes in industrial structure are a direct driver of China's economic growth. The industrial structural adjustment has created and provided the necessary elements for the development of a tourism industry, which supports the scale development of the tourism industry and improves the contribution rate of the tourism industry to economic growth. Therefore, based on quantitative measurement of industrial structure, we put tourism, industrial structure and economic growth into a unified framework to carry out empirical research. We found that the tourism industry had a significant positive impact on economic growth. The rationalization of industrial structure had an inhibitory effect on economic growth, while the optimization of industrial structure had a positive impact on economic growth. The 'structural effect' of the optimization of industrial structure on economic growth was greater than the 'imbalance effect' of the rationalization of industrial structure. Finally, the rationalization of industrial structure inhibited the impact of tourism on economic growth, while the optimization of industrial structure positively adjusted the impact of tourism on economic growth. In the policy making process, the government should emphasize the optimization of industrial structure and pay attention to the rationalization of industrial structure to create conditions for the positive adjustment effect of industrial structure on the impact of the tourism industry on economic growth.
\end{abstract}

Key words: tourism industry; rationalization of industrial structure; optimization of industrial structure; economic growth; China 